\title{
Endoscopic Ultrasound for Solid and Cystic Neoplasms of the Pancreas
}

\author{
Karim M. Eltawil ${ }^{1}$ and Michele Molinari ${ }^{2}$ \\ ${ }^{1}$ Dalhousie University, Department of Surgery, Queen Elizabeth II \\ Health Sciences Centre, Rm 6-302 Victoria Building,Halifax, Nova Scotia \\ ${ }^{2}$ Associate Professor of Surgery, Rm 6-302 Victoria Building, Halifax, Nova Scotia
}

Canada

\section{Introduction}

Endoscopic ultrasound (EUS) was introduced in clinical practice in $1980^{1}$ and during the last few decades the quality of instrumentation has improved significantly. The first commercially available radial echoendoscope was introduced in Japan ${ }^{2}$ and then in Europe 3 in the mid to late 1980s. At that time, radial probes were used for fine needle aspiration (FNA). Only in the early 1990s EUS-FNA become technologically practical with the introduction of linear echoendoscopes that generated ultrasonic images parallel to the shaft of the instrument. With this modification, needles could be guided into areas of interest. Soon after this improvement, the first report of EUS-FNA of the pancreas was published 4 and numerous other publications have followed ${ }^{5-8}$. Later on, mechanical probes have been replaced by electrical probes that allowed expansion of the diagnostic capacity of EUS. More recently, the addition of color Doppler ultrasonography, injection of contrasts for ultrasound and the application of elastography has further extended the clinical use of EUS for hepatobiliary and pancreatic diseases. The fact that EUS is able to provide direct visualization of the walls of the gastrointestinal tract and direct the placement of needles for cytology or histology specimens 5,9 , makes this technique very useful for the diagnosis of benign and malignant diseases of these organs that are difficult to reach percutaneouly. In recent years diagnostic modalities such as multidetector-multiphasic CT with pancreatic protocols, magenetic resonance imaging (MRI) and positron emission tomography (PET) scans have improved significantly the pre-operative tumor staging of pancreatic malignancies. Nevertheless, a significant proportion of patients will benefit from EUS-FNA for confirmation of pancreatic neoplasm and assessment of the planes along the vascular superior mesenteric trunk ${ }^{10}$.

\section{Epidemiology of pancreatic neoplasms}

Pancreatic adenocarcinoma is the fourth leading cause of cancer related mortality in the United States with estimated 42,500 new cases and 35,000 deaths from the disease each year 11. In industrialized countries, the incidence of pancreatic adenocarcinoma (11 per 100,000 individuals) ranks second after colorectal cancer among all gastrointestinal malignancies ${ }^{12}$. More than $80 \%$ of PCs are diagnosed in patients older than 60 and almost $50 \%$ have distant metastases at the time of presentation ${ }^{13,14}$. Men are more frequently affected than women 
(Relative Risk $(\mathrm{RR})=1.3$ ) and individuals of African American descent in comparison to Caucasians $(R R=1.5)^{15}$. Analysis of overall survival shows that the prognosis of PC is still quite poor despite the fact that 1-year survival has increased from 15.2\% (period between 1977-1981) to $21.6 \%$ (period between 1997-2001) and 5-year survival has increased from $3 \%$ (period between 1977-1986) to 5\% (period between 1996-2004) ${ }^{16}$.

\section{Classification of pancreatic neoplasms}

The vast majority (90\%) of pancreatic cancers (PC) are malignant tumors originating from pancreatic ductal cells ${ }^{17}$. Anatomically, $78 \%$ of PCs are located in the head, and the remaining $22 \%$ are equally distributed in the body and in the tail ${ }^{18}$. The most common

\begin{tabular}{|c|c|}
\hline EPITHELIAL TUMORS & NON-EPITHELIAL TUMORS \\
\hline Benign Pancreatic Tumors & Endocrine Tumors \\
\hline Serous Cystoadenoma & Insulinoma (Incidence: 70-80\%) \\
\hline Mucinous Cystoadenoma & Gastrinoma (Incidence: $20-25 \%$ ) \\
\hline Intraductal Papillary Mucinous & \\
\hline Neoplasm (IPMN) & VIIPoma (Incidence: 4\%) \\
\hline Mature Teratoma & Glucagonoma (Incidence: 4\%) \\
\hline Borderline Pancreatic Tumors & Somastatinoma (Incidence: $<5 \%$ ) \\
\hline Mucinous Cystic Neoplasm with & Carcinoid (Incidence: $<1 \%$ ) \\
\hline Moderate Dysplasia & \\
\hline $\begin{array}{l}\text { Intraductal Papillary Mucinous } \\
\text { Neoplasm with Moderate Dysplasia }\end{array}$ & ACTHoma (Incidence: $<1 \%$ ) \\
\hline $\begin{array}{l}\text { Solid-pseudopapillary Neoplasm } \\
\text { (SPPN) }\end{array}$ & GRFoma (Incidence: <1\%) \\
\hline Malignant & PTH-like-oma (Incidence: $<1 \%$ ) \\
\hline Ductal Adenocarcinoma & Neurotensinoma (Incidence: $<1 \%$ ) \\
\hline Mucinous non-cystic carcinoma & Non-functional tumors (Incidence 30-50\%) \\
\hline Signet ring cell carcinoma & Mesenchymal Neoplasms \\
\hline Undifferentiated (anaplastic) carcinoma & Leiomyoma \\
\hline $\begin{array}{l}\text { Undifferentiated carcinoma with } \\
\text { osteoclast-like giant cells }\end{array}$ & Lipoma \\
\hline Mixed ductal-endocrine carcinoma & Neurofibroma - Ganglioneuromas \\
\hline Serous Cystoadenocarcinoma & Hemangyoma - Lymphangioma \\
\hline Mucinous Cystoadenocarcinoma & Granular Cell Tumors \\
\hline Intraductal Papillary-Mucinous & Schwann Cell Tumors \\
\hline $\begin{array}{l}\text { Carcinoma } \\
\text { Acinar Cell Carcinoma }\end{array}$ & Gastrointestinal Stroma Tumors (GIST) \\
\hline Medullary Carcinoma & B-cell Lymphomas \\
\hline Acinar Cell Cystoadenocarcinoma & Metastatic Tumors \\
\hline Pancreatoblastoma & Renal Cell Carcinoma \\
\hline Solid-pseudopapillary Carcinoma & Melanoma \\
\hline Others & Breast Cancer \\
\hline & Squamous Cell Carcinoma \\
\hline Secondary Tumors & Endometrioid Adenocarcinoma \\
\hline & Osteosarcoma \\
\hline
\end{tabular}

Table 1. Tumor Classification 
clinical presentations are progressive weight loss and anorexia, mid abdominal pain and jaundice. Pancreatic neoplasms are classified in benign or malignant according to the cytological characteristics. These can be further divided into endocrine or exocrine tumors according to the function of their cells and into cystic or solid according to the macroscopic features of the lesion. Recent advances in surgical pathology techniques integrated with molecular biology have allowed advances in the modern classification of pancreatic neoplasms. A summary of the clinico-pathological features of the different categories of pancreatic lesions is shown in Table 1.

\section{Conventional diagnostic modalities for pancreatic cancer}

\subsection{Abdominal ultrasound}

Trans-abdominal ultrasound (US) is often used as a screening test ${ }^{19}$. Its sensitivity ranges between $48 \%{ }^{8}$ and $89 \%{ }^{20}$ with accuracy between $46 \%{ }^{8}$ and $64 \%^{21}$. Small tumors measuring less than $1 \mathrm{~cm}$ are detected by US in only $50 \%$ of cases while the sensitivity increases to $95.8 \%$ for tumors larger than $3 \mathrm{~cm}^{20}$. US has a relatively low performance profile for staging of pancreatic tumors as its sensitivity for lymph nodes involvement ranges only between 8 17 to $57 \%{ }^{20}$. Color Doppler US has been used to assess possible involvement of the portal vein and superior mesenteric vessels with a sensitivity ranging between $50 \% 22$ and $94 \% 23$ specificity between $80 \%$ and $100 \% 22$ and accuracy between $81 \%$ and $95 \% 19$.

\subsection{Computed Tomography}

On contrast CT, pancreatic adenocarcinoma appears as an ill-defined, hypo attenuating focal mass with dilatation of the upstream pancreatic and or biliary duct 24 . The optimum visualization of the pancreas requires imaging acquisition obtained during both arterial and portal phases ${ }^{25}$ with sensitivity and specificity of $77 \%$ and $100 \%$ respectively for lesions less than $2 \mathrm{~cm}^{26}$. In a multicentric trial, the diagnostic accuracy of contrast CT for resectability was $73 \%$ with $90 \%$ PPV for non resectability 27 . With the advent of multi detector CT scanners (MDCT) the pancreas can be imaged at a very high spacial and temporal resolution 28,29 . Recent studies have shown that NPV for respectability was $87 \%$ for MDCT compared to $79 \%$ for conventional helical CT 30 and with accuracy between $85 \%$ and $95 \% 31,32$.

\subsection{Magnetic Resonance Imaging (MRI-MRCP)}

In most institutions, MRI is performed when other imaging modalities provide insufficient data for the clinical staging of the tumor or when treatment planning can not be based on the images obtained by other techniques. Several studies have shown that MRI is superior to CT scan for the detection and staging of pancreatic adenocarcinoma ( $100 \%$ vs. $94 \%$ respectively) ${ }^{33-36}$. The use of MRI-MRCP for pancreatic malignancies is supported by a prospective analysis showing that MRI-MRCP was superior to CT in differentiating malignant from benign lesions and MRI-MRCP had better sensitivity ( $92 \%$ vs. $76 \%$ ), specificity ( $85 \%$ vs. $69 \%)$, accuracy $(90 \%$ vs. $75 \%)$, PPV (95\% vs. $88 \%)$ and NPV $(79 \%$ vs. $50 \%$ ) compared to CT 37.

\subsection{Positron Emission Tomography}

18F-2fluoro-2-deoxy-D-glucose (FDG) accumulated by tumor cells provides PET the advantage of combining metabolic activity and imaging characteristics. Newly developed PET scanners can detect small PC up to $7 \mathrm{~mm}$ in diameter and diagnose metastatic disease in 
about $40 \%$ of cases 38,39 . A Japanese study found that the overall sensitivity of PET-CT was superior to contrast CT ( $92 \%$ vs. $88 \%)$ and that PET was better at detecting bone metastases $(100 \%$ vs. $12 \%)$. However, CT scan was superior for the evaluation of vascular invasion $(100 \%$ vs. $22 \%)$, involvement of para-aortic regional lymph nodes (78\% vs. $57 \%)$, identification of peritoneal dissemination $(57 \%$ vs. $42 \%)$ and hepatic metastases $(73 \%$ vs. $52 \%)^{40}$.

\subsection{Treatment of pancreatic neoplasms}

Solid tumors of the pancreas are typically associated with malignancy, whereas cystic tumors more often tend to be benign ${ }^{41}$. Due to the difficulties in differentiating benign from malignant lesions, resection is often indicated when patient's conditions and tumor stage allows it 42 . Surgical resection with negative margins is the only potential curative treatment for pancreatic malignancies but unfortunately, even when surgery is performed successfully, recurrent disease is frequent and long term survival is expected only for 5-15\% of patients ${ }^{17}$. According to the United States Surveillance and Epidemiology End Results registries, the 5-year relative survival for the period between 1999 and 2006 was $22.5 \%$ for localized and $1.9 \%$ for metastatic tumors ${ }^{43}$. The majority of tumors are diagnosed when locally advanced or with early metastases, and only $20 \%$ are suitable for resection at the time of diagnosis. Despite the improvements in surgical techniques and advances in perioperative supportive care that have reduced the mortality rates to less than $5 \%$ in high volume centers, pancreatic surgery remains challenging 44-46. Therefore, pre-operative accurate staging is fundamental in identifying patients who would benefit from surgery. EUS has been shown to play an important role in preoperative diagnosis and tumor staging as it provides high resolution images of the pancreas without interference of bowel gas ${ }^{47}$.

\subsection{EUS equipment and techniques}

EUS is usually performed with patients positioned in the left dcubitus and under conscious sedation. The transducer located in the tip of the oblique-viewing fiberscope is inserted as far as the second portion of the duodenum, and scanning is done with a de-areated water filled ballon applied to the tip of the echoendoscope. After examination of the pancreatic head, the ecoendoscope is drawn backward to the stomach, and EUS of the body and tail of the pancreas is performed. The frequency usually used to assess the pancreas and surrounding organs during EUS ranges between 5 and $12 \mathrm{MHz}^{48}$. During the last decade, intraductal US (IDUS) has been possible by the introduction of miniprobes measuring 1.7$2.4 \mathrm{~mm}$ in outer diameter that can be advanced in the common bile and pancreatic ducts utilizing scanning frequencies ranging between $10-30 \mathrm{MHz}$ and obtaining a maximum tissue view penetration of approximately $2 \mathrm{~cm} \mathrm{1,48}$. The miniprobe is initially introduced into the papilla of Vater and advanced into the pancreatic or bile duct beyond the area of interest and then it is slowly pulled back. The location of the miniprobe can be confirmed by using fluoroscopy as it is usually done during regular endoscopic retrograde cholangiopancreatography (ERCP). IDUS is able to visualize only limited parts of the pancreas and surrounding structure such as the splenic vessels, portal vein, superior mesenteric artery and vein and extrahepatic duct.

\subsection{Indications for Endoscopic Ultrasound and Fine Needle Aspiration (EUS-FNA)}

The most common indication for EUS-FNA of the pancreas is for evaluation of pancreatic masses with atypical characterisitics on cross sectional images or for optimal pre-operative 
staging (Table 2). Differential diagnosis of pancreatic masses includes malignant and benign neoplasms, chronic pancreatitis, lymphoma and metastases. Approximately $90 \%$ of pancreatic neoplasms are adenocarcinomas, 5\% are cystic lesions, and $2-5 \%$ are neuroendocrine tumors. Metastatic lesions to the pancreas, primarily from renal cancer, lung cancer, and lymphomas represent a small percentage. Because cystadenocarcinomas ${ }^{49}$ and neuroendocrine tumors ${ }^{50}$ have a significantly better prognoses than pancreatic adenocarcinoma, accurate cytologic preoperative identification can significantly alter the subsequent management of these patients ${ }^{51}$. In general, EUS has been shown to be superior to CT, MRI, and ERCP 52 in the diagnosis of pancreatic diseases as an imaging modality $2,5,53,54$. The current sensitivity of EUS is in the range of $95-100 \%$. During the last decades, the diagnostic advantages of EUS for pancreatic pathology have been challenged by the advances of other cross sectional modalities such as CT, MRI and PET scans 5556 . When combined with FNA capabilities, EUS has the advantage of being able to sample suspicious lesions. The one area where malignancies can be still easily missed by EUS, even with EUSFNA, is in the setting of underlying chronic pancreatitis ${ }^{4,53,57-59}$. No single or combination of imaging modalities has yet proven accurate in definitively determining when a patient with chronic pancreatitis has developed pancreatic cancer. The technique of EUS-guided FNA involves passing an 18 to 22 gauge metal needle through the biopsy port of a linear echoendoscope under real-time guidance into an endosonographically visualized pancreatic mass. The needle is then moved back and forth several times (5-10 passes) with varying degrees of negative pressure to collect cells or small tissue samples that are then deposited on cytology slides for immediate fixation and staining ${ }^{60}$. EUS-FNA of primary pancreatic malignancies is able to provide a definitive diagnosis in $80-93 \%$ of cases $8,54,57,61-63$. The ability to have a cytopathologist on site who can provide immediate feedback on the quality and adequacy of the specimens obtained by FNA is extremely important for the accurate diagnosis ${ }^{62,63}$. Choosing what part of a pancreatic mass to aspirate is something of an art and comes with experience. The most difficult pancreatic masses to aspirate are the ones located near the uncinate process as it can be very hard to direct the needle to enter the lesion around the second and third portion of the duodenum. The best yield of diagnostic cells usually seems to come from $1 \mathrm{~cm}$ to $2 \mathrm{~cm}$ deep to the margin of the tumor. Color flow Doppler can be used prior to EUS-FNA to help avoid vessels overlying the proposed path of the aspiration needle such as are seen when there is underlying portal vein or splenic vein obstruction. Similarly to CT and ultrasound-guided FNA or biopsy, the overall complication rate secondary to EUS-FNA of the pancreas is about 1-2\% 6,8,58,61,64. The major complications reported with EUS-FNA are bleeding, pancreatitis, and infection but mortality is very rare

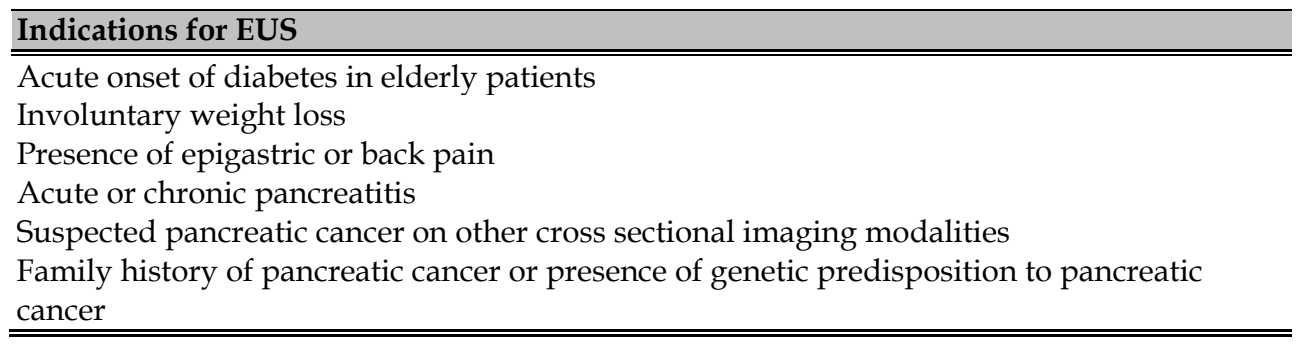

Table 2. Common Indications for Endoscopic Ultrasound 
and usually caused by uncontrollable hemorrhage 65 that is more likely when the patient has portal hypertension. Pancreatitis after EUS-FNA is most likely to occur in patients already being evaluated for recurrent pancreatitis and when the FNA needle is passed through more than $2 \mathrm{~cm}$ to $3 \mathrm{~cm}$ of normal pancreas to obtain a specimen. Bacteremia following EUS-FNA for solid tumors is quite uncommon while EUS-FNA of cystic pancreatic lesions has a higher risk of infectious complications and broad-spectrum intravenous antibiotics are routinely recommended. The risk of cancer seeding by EUS-FNA appears to be significantly lower when compared to percutaneous FNA 66.

\subsection{EUS-FNA for benign pancreatic lesions}

Indications and impact of EUS-FNA for benign disease other than pancreatic cystic lesions is still in evolution as it appears to be safe but does not add significantly to the diagnostic accuracy of EUS or other cross sectional imaging tests ${ }^{67}$.

\subsection{Ultrasonographic characteristics}

Pancreatic adenocarcinoma often appears as a mass with irregular echogenicity due to the irregulary arranged carcinomatous canaliculi or coagulative necrosis of the neoplastic cells superimposed on a hypoechoic background ${ }^{68}$. Small pancreatic cancers instead, can often have homogeneous and hypoechoic echogeneicity that can mimic benign diseases such as focal pancreatitis, pseudotumors or islet cell neoplasms that have clear margins, smooth contour and regular central echogenicity ${ }^{48}$. When compared to CT scan and ERCP, EUS performs better for the detection of small pancreatic cancers (less than $2 \mathrm{~cm}$ in diameter) and it is currently indicated when patients are suspected to have early stage tumors or when undergoing screening for familial pancreatic cancer as it is the most sensitive diagnostic test for lesions measuring less than $1 \mathrm{~cm}$ in diameter 69,70 .

\section{Differential diagnosis of pancreatic lesions}

Differentiation between pancreatic malignancies from inflammatory masses has been very challenging with the use of cross sectional imaging modalities such as US, CT scans, MRI and ERCP. EUS-FNA appears to be the best diagnostic strategy as it combines the ability of ultrasound imaging of the pancreatic lesions and the ability of obtaining samples for cytological or histological evaluation. Recent studies have reported that adequate specimen acquisition is possible in $97 \%$ of cases with accurate differential diagnosis in $87 \%$ of patients 48. Sensitivity, specificity, positive predictive value and negative predictive value for EUSFNA were: $85 \%, 100 \%, 100 \%$ and $53 \%$ respectively 48 (Table 3). One of the major pitfalls is over interpretation of a lesion as positive for malignancy as a result of contamination of dysplastic cells when the needle traverses an area of high-grade dysplasia of the gastrointestinal tract mucosa. It is equally important that benign mucosal glandular cells in the aspirate of the lymph node not be over interpreted as metastasis. Although EUS-FNA is a very useful diagnostic technique for the differential diagnosis of patients with pancreatic lesions, it has to be kept in mind that even if the results of the test are negative for malignancy, pancreatic cancer can not be completely excluded. Currently, EUS-FNA should be still used in conjuction with other imaging modalities and repeated when clinical suspicion is suggestive for the possibility of malignancy (Table 4). 


\begin{tabular}{lccc}
\hline Diagnostic Performance & CT & EUS & EUS-FNA \\
\hline \hline Sensitivity & $63-84 \%$ & $95-100 \%$ & $79-95 \%$ \\
Specificity & $35-93 \%$ & $19-81 \%$ & $69-100 \%$ \\
Negative Predictive Value & $12-49 \%$ & $48-100 \%$ & $31-78 \%$ \\
Positive Predictive Value & $89-99 \%$ & $85-98 \%$ & $94-100 \%$ \\
Accuracy & $70-88 \%$ & $97-98 \%$ & $81-96 \%$ \\
\hline \hline
\end{tabular}

Table 3. Diagnsostic Performance of Endoscopic Ultrasound and Computerized Tomography for Solid Pancreatic Cancers

\begin{tabular}{|c|c|c|c|c|}
\hline & & CT & EUS & EUS-FNA \\
\hline \multirow{4}{*}{ 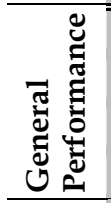 } & Sensitivity & 63-84\% & $95-100 \%$ & $799-95 \%$ \\
\hline & Negative Predictive Value & $12-49 \%$ & $48-100 \%$ & $31-78 \%$ \\
\hline & Positive Predictive Value & $89-99 \%$ & $85-98 \%$ & $94-100 \%$ \\
\hline & Accuracy & $70-88 \%$ & $97-98 \%$ & $81-96 \%$ \\
\hline \multirow{5}{*}{ 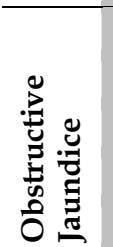 } & Sensitivity & $51-80 \%$ & $92-100 \%$ & $71-94 \%$ \\
\hline & Specificity & $16-100 \%$ & $1-99 \%$ & $16-100 \%$ \\
\hline & Negative Predictive Value & $1-36 \%$ & $25-100 \%$ & $3-60 \%$ \\
\hline & Positive Predictive Value & $88-100 \%$ & $88-100 \%$ & $91-100 \%$ \\
\hline & Accuracy & $53-81 \%$ & $89-100 \%$ & $72-94 \%$ \\
\hline \multirow{5}{*}{ 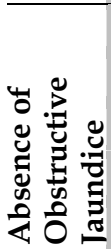 } & Sensitivity & $70-98 \%$ & $87-100 \%$ & $80-100 \%$ \\
\hline & Specificity & $24-91 \%$ & $16-84 \%$ & $63-100 \%$ \\
\hline & Negative Predictive Value & $24-91 \%$ & $40-100 \%$ & $52-100 \%$ \\
\hline & Positive Predictive Value & $70-98 \%$ & $69-96 \%$ & $86-100 \%$ \\
\hline & Accuracy & $65-93 \%$ & $73-97 \%$ & $85-100 \%$ \\
\hline
\end{tabular}

Table 4. Diagnostic Performance of Endoscopic Ultrasound with and without Fine Needle Aspiration in Comparison to Computerized Tomography for Pancreatic Cancers in the Presence and Absence of Obstructive Jaundice

\subsection{Cancer staging}

The accuracy of EUS for the stage of patients with pancreatic cancer is superior to US and CT scans with values ranging between 85 and 100\% in comparison to $64-66 \%$ for CT and 61$64 \%$ for US 55,71. The EUS accuracy in staging pancreatic cancer does not depend on the use of radial or linear scanners 65 . Radial scanners offer a better overview of surrounding structures, whereas linear scanners allow the safe execution of tissue sampling. Initial studies showed excellent accuracy up to $94 \%$, but later publication reported lower values ranging between $63 \%$ and $78 \% 55,72-76$. Overall, EUS-FNA is highly sensitive (84\%), specific $(97 \%)$, accurate $(84 \%)$ and has a high positive predictive value $(99 \%)$, but relatively low negative predictive value $(64 \%)^{77}$ (Table 5). A major problem in staging pancreatic cancer is the prediction of resectability as the best chance for long-term survival occurs in patients with localized disease undergoing resection. The primary goal of surgical therapy is to achieve a margin-negative $\mathrm{R} 0$ resection with minimal postoperative complications and a secondary important goal is to avoid unnecessary laparotomies for unresectable tumors ${ }^{78}$. 
Combining the pre-operative utilization of CT and EUS proved to be the method with the highest accuracy compared to each single technique to predict tumor resectability 79 .

In this context, a preoperative assessment of $\mathrm{R} 0$ resectability becomes critically important. Radiologic staging with EUS and CT or MRI is currently used to identify patients who may be resectable. The criteria of unresectability of pancreatic cancer include evidence of distant metastasis, tumor enchroachment (defined as tumor surrounding the vessel more than 180 degrees) of arteries such as the celiac artery, hepatic artery, superior mesenteric artery (SMA) or massive venous invasion with thrombosis. Portal or superior mesenteric venous invasion without thrombosis or obliteration of vessels can still be classified as resectable tumors. A recent study comparing the roles of EUS, CT, MRI and angiography in the assessment of pancreatic cancer staging and respectability, has shown that CT scan was the most accurate in assessing the stage of the tumor (73\%), locoregional invasion $(74 \%)$, vascular involvement $(83 \%)$, distant metastases (88\%), final TNM stage (46\%) and overall tumor resectablity $(83 \%)^{76}$. Although EUS appeared to be superior to detect smaller tumors not visualized by CT scan it is important to recognize that most surgeons would probably not rely on EUS alone before making important therapeutic decisions about surgical resections ${ }^{80}$.

\begin{tabular}{|l|cc|cc|}
\cline { 2 - 5 } \multicolumn{2}{c|}{} & \multicolumn{2}{c|}{ No Discrete Mass on CT } & \multicolumn{2}{c|}{ Discrete Mass on CT Scan } \\
\hline \hline Sensitivity & EUS & EUS-FNA & EUS & EUS-FNA \\
Specificity & $82-100 \%$ & $65-99 \%$ & $93-100 \%$ & $77-96 \%$ \\
Negative Predictive Value & $29-96 \%$ & $59-100 \%$ & $0-71 \%$ & $29-100 \%$ \\
Positive Predictive Value & $48-100 \%$ & $40-97 \%$ & na & $7-70 \%$ \\
Accuracy & $68-99 \%$ & $79-100 \%$ & $85-99 \%$ & $92-100 \%$ \\
\hline \hline
\end{tabular}

Table 5. Diagnostic Value of Performing EUS-FNA Along with Spiral CT in Patients with Suspected Pancreatic Cancer

\subsection{Conclusions}

EUS-FNA has greatly impacted the diagnostic management of patients affected by pancreatic masses in conjunction with other cross sectional imaging tests. EUS is the best

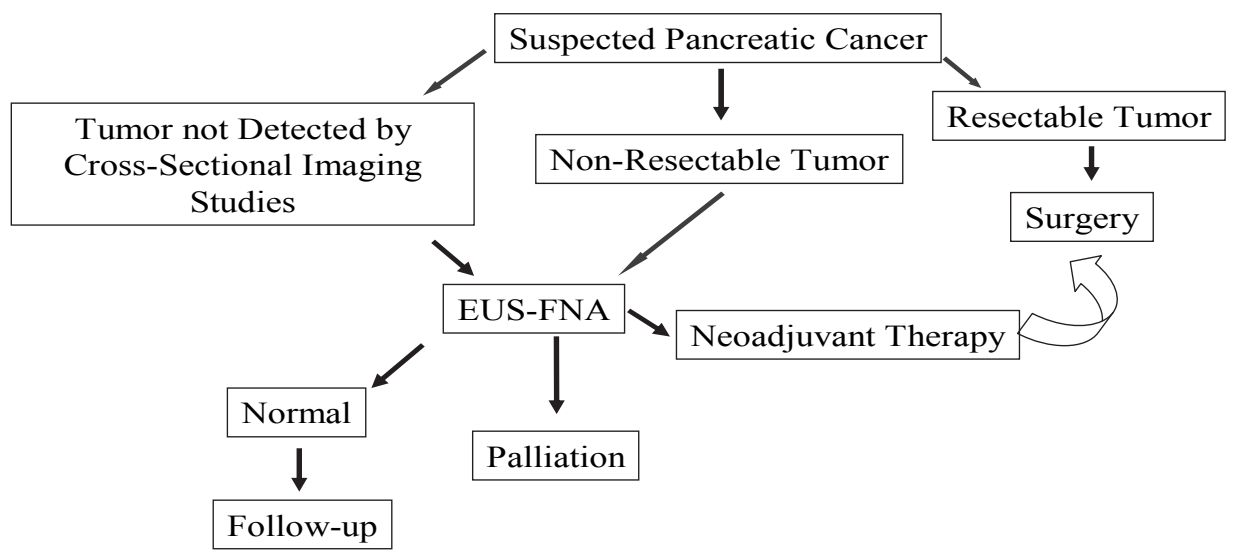

Fig. 1. Flow Chart for the Evaluation and Management of Patients with Suspected Pancreatic Malignancies 
method for tissue diagnosis and it is extremely useful for the management of patients who are not surgical candidates and who require neo-adjuvant or palliative chemoradiation therapy. Conversely, pre-operative tissue diagnosis is not indispensable for resectable tumors and therefore EUS plays a lesser role in this group of patients. In recent years, EUS has assumed an important interventional role in the management of patients who are affected by debilitating pancreatic cancer pain as it is extremely useful in obtaining celiac plexus block for long term analgesic effects. Current role of EUS and EUS-FNA is summarized in Figure 1.

\section{Pancreatic cystic lesions}

Pancreatic cystic lesions (PCLs) are commonly identified due to increased use of crosssectional imaging in patients with non-specific abdominal complaints. Although their exact prevalence is unknown, it is estimated to range from $1 \%$ to $2.6 \%$ of the general population based on large scale observational imaging studies using MDCT 81,82 . Pancreatic cystic lesions are strongly associated with increasing age and Asian race ${ }^{82}$. Their relative frequency varies substantially geographically and by institution (primary vs. secondary) due to different practices and patient populations ${ }^{83}$. In addition, the prevalence of PCLs including intraductal papillary mucinous neoplasms (IPMNs) was found to be higher among patients on hemodialysis compared to the normal population 84 .

Inflammatory pseudocysts represent about $75 \%$ of pancreatic cysts; however they are not classified as true PCLs since they are non-epithelial inflammatory fluid collections associated with acute or chronic pancreatitis 85 . Based on surgical pathology, PCLs are classified according to the characteristics of the cells lining the cyst in benign, premalignant and malignant 86 (Table 6).

Serous cystadenomas (SCAs), mucinous cystadenocarcinomas (MCAs) and IPMNs represent $90 \%$ of PCLs and only the mucin producing neoplasms have been described to have risk of malignancy ${ }^{87}$. In a small percentage of patients, solid malignant tumors such as adenocarcinoma, neuroendocrine tumors and other less common causes can present with cystic degeneration 88 .

\subsection{Limitations of radiological imaging modalities for the diagnosis of PCLs}

Trans-abdominal ultrasound (US) is a safe and cheap diagnostic modality that can be used to diagnose PCLs, however, its sensitivity and specificity are often affected by the operator's experience and the technical characteristics of the machine ${ }^{89}$. In addition, the deep position of the pancreas and the interposition of other organs such as the stomach and the transverse colon limit the capacity of US to identify small PCLs. The overall sensitivity of US in detecting pancreatic lesions ranges from $48 \% 8$ to $89 \% 20$.

The majority of studies describing the role of CT and MRI in the diagnosis of PCLs have been small and retrospective. Relying on radiological characteristics alone can be misleading, with up to $40 \%$ of serous and mucinous lesions being misdiagnosed as pseudocysts 85,90 . Reported overall diagnostic accuracy for these lesions has been highly variable ranging between $20 \%$ and $83 \%$ 91-93. (Table 7)

In a large group of patients, accurate preoperative diagnosis of PCLs was reported in $20 \%$ for serous cystadenoma, $30 \%$ for mucinous cystadenoma and $29 \%$ for mucinous cystadenocarcinoma, as the majority of these lesions were misdiagnosed as pseudocysts ${ }^{92}$. MRI is equal or slightly superior to CT in diagnosing PCLs except in its limited ability to demonstrate calcifications in the tumor wall or septa ${ }^{94}$. 
Pseudocysts (no epithelial lining)

Conventional pseudocysts

Paraduodenal wall cyst (cystic dystrophy)

Infection-related pseudocysts

Cysts with mucinous epithelium

Intraductal papillary mucinous neoplasms

Intraductal oncocytic papillary neoplasms

Mucinous cystic adenoma

Mucinous cystic adenocarcinoma

Mucocele

Retention cysts

Serous (clear-cell) cystic tumors

Serous cystadenoma

VHL-associated pancreatic cysts

Serous cystadenocarcinomas (Extremely rare, case reports)

Squamous-lined cysts

Lymphoepithelial cysts

Epidermoid cysts within intrapancreatic accessory spleen

Dermoid cysts

Squamoid cyst of pancreatic ducts

Cysts lined by acinar cells

Acinar cell cystadenocarcinomas

Acinar cell cystadenomas (cystic acinar transformation)

Endothelial-lined cysts

Lymphangiomas

Degenerative or necrotic changes in solid tumors

Solid-pseudopapillary tumor

Cystic change in ordinary ductal adenocarcinoma

Cystic pancreatic endocrine neoplasia (islet cell tumors)

Cystic mesenchymal neoplasms

Other rare cystic lesions

Cystic hamartomas

Endometriotic cyst

Metastatic cystic neoplasms

Congenital or developmental cysts

Others

VHL $=$ Von Hippel-Lindau

Table 6. Pancreatic cystic lesions classified by cells lining the cavity 
For IPMN, magnetic resonance cholangiopancreatography (MRCP) seems to be superior to endoscopic retrograde cholangiopancreatography (ERCP) in detecting cysts communicating with the main pancreatic duct ${ }^{95}$.

\subsection{Endoscopic ultrasonography}

Endoscopic ultrasound (EUS) allows high resolution imaging of the pancreas with the ability to provide fine morphological details. The combination of fine-needle aspiration (FNA) cytology with the other recently available diagnostic markers has further increased its diagnostic accuracy ${ }^{96}$. Indications for EUS-FNA should be considered based on diagnostic accuracy of alternative modalities, costs, patient comfort and safety 97 and should be performed only when the information obtained has the potential to alter patient's management ${ }^{98}$. EUS-FNA should not be performed when there is inability to clearly visualize the target lesion, presence of large vessels interposed in the path between the needle and the lesion, bleeding diathesis and for patients at high risk of tumor seeding 98 such as those with cholangiocarcinoma who are considered for liver transplantation ${ }^{99}$. Once a cystic lesion is identified, the main clinical issue is the characterization and eventual therapeutic approach. Diagnostic accuracy of EUS imaging alone for differentiating malignant versus premalignant or benign lesions is ranging between $82 \%$ and $96 \% 100-103$.

The endosonographic features suggestive of malignancy are: wall thickness of $3 \mathrm{~mm}$ or greater, macroseptations with cystic compartments greater than $10 \mathrm{~mm}$, presence of a mass or intramural growth or cystic dilation of the main pancreatic duct. These features have a sensitivity of $91 \%$, a specificity of $60 \%$ and an accuracy of $72 \%$ in predicting malignant or potentially malignant PCLs ${ }^{104}$. The sensitivity, specificity, positive predictive value (PPV), negative predictive value (NPV) and accuracy of EUS in comparison to other imaging modalities is summarized in Table 7

Despite EUS alone is a very sensitive test, EUS-guided fine needle aspiration (FNA) provides additional information for the characterization of PCLs. In a study by Frossard et al., the results of EUS and EUS guided FNA were compared with the final surgical pathology report. The sensitivity, specificity, PPV and NPV of EUS-guided FNA in this study were $97 \%, 100 \%, 100 \%$ and $95 \%$ respectively ${ }^{102}$. On the other hand, corresponding values for EUS imaging alone were $71 \%, 30 \%, 49 \%$ and $40 \%$ respectively ${ }^{102}$. Yet, the overall sensitivity and accuracy of EUS-FNA cytology remains widely variable with average sensitivity and accuracy around 50\% 62,103,112,113.

\subsection{Cytology}

The aspirated cyst fluid is generally analyzed for tumor markers, chemical and molecular analysis. Solid component associated with PCLs or regional lymph nodes can be aspirated for cytology or histology. EUS guided FNA is safe and rare complications include pancreatitis $(2-3 \%)$, intracystic hemorrhage $(<1 \%)$ and infection $(<1 \%)$. The administration of antibiotic during the procedure is a common practice even if there are no data to support it 114. Tumor cell seeding has been a significant concern; there is limited evidence on the actual rise of tumor spread by EUS-FNA ${ }^{115}$. Recent study has shown that EUS-FNA has a decreased risk of peritoneal tumor spread as compared with computed tomography-guided FNA $(2.2 \%$ vs. $16.3 \%){ }^{66}$. During EUS-FNA, the operator should always avoid to insert the needle through malignant tissue to reach a suspicious lesion. An example of this may be a patient with gastric or esophageal cancer and a suspicious lymph node adjacent to the primary tumor as the needle would have tumor entrapped into the channel that could contaminate the final results. 


\begin{tabular}{|c|c|c|c|c|c|c|c|}
\hline $\begin{array}{c}\text { Diagnostic } \\
\text { modality }\end{array}$ & Author & Year & $\begin{array}{c}\text { Sensitivity } \\
(\%)\end{array}$ & $\begin{array}{c}\text { Specificity } \\
(\%)\end{array}$ & $\begin{array}{c}\text { PPV } \\
(\%)\end{array}$ & $\begin{array}{l}\text { NPV } \\
(\%)\end{array}$ & $\begin{array}{c}\text { Accuracy } \\
(\%)\end{array}$ \\
\hline \multirow{6}{*}{ US } & Giovanni et al 8 & 1994 & \multirow{6}{*}{$48-95$} & \multirow{6}{*}{$40-91$} & \multirow{6}{*}{92} & \multirow{6}{*}{100} & \multirow{6}{*}{$46-64$} \\
\hline & Bottger et al 20 & 1998 & & & & & \\
\hline & Rosch et al ${ }^{3}$ & 1991 & & & & & \\
\hline & Niederau et al 105 & 1992 & & & & & \\
\hline & Palazzo et al 21 & 1993 & & & & & \\
\hline & Tanaka et al106 & 1996 & & & & & \\
\hline \multirow{3}{*}{ Doppler US } & Candiani et al 107 & 1998 & \multirow{3}{*}{$50-94$} & \multirow{3}{*}{$80-100$} & \multirow{3}{*}{79} & \multirow{3}{*}{88} & \multirow{3}{*}{$81-95$} \\
\hline & Casadei et al23 & 1998 & & & & & \\
\hline & calculli et al108 & 2002 & & & & & \\
\hline \multirow{3}{*}{ EUS } & Akahoshi et al 72 & 1998 & \multirow{3}{*}{98} & \multirow{3}{*}{97} & \multirow{3}{*}{94} & \multirow{3}{*}{100} & \multirow{3}{*}{90} \\
\hline & Sedlack et al ${ }^{104}$ & 2002 & & & & & \\
\hline & Legmann et al 55 & 1998 & & & & & \\
\hline $\begin{array}{l}\text { Contrast } \\
\text { enhanced US }\end{array}$ & Dietrich et al109 & 2008 & 90 & 100 & 100 & 86 & 93 \\
\hline \multirow{2}{*}{ CT } & Bronstein et al 26 & 2004 & \multirow{2}{*}{77} & \multirow{2}{*}{100} & \multirow{2}{*}{ na } & \multirow{2}{*}{ na } & \multirow{2}{*}{73} \\
\hline & Megibow et al 27 & 1995 & & & & & \\
\hline \multirow{4}{*}{ MDCT } & Park et al110 & 2009 & \multirow{4}{*}{$83-91$} & \multirow{4}{*}{$63-75$} & \multirow{4}{*}{80} & \multirow{4}{*}{87} & \multirow{4}{*}{$85-95$} \\
\hline & Vargas et al30 & 2004 & & & & & \\
\hline & Diehl et al 31 & 1998 & & & & & \\
\hline & Schima et al 33 & 2002 & & & & & \\
\hline MRI-MRCP & Anderssonet al ${ }^{37}$ & 2005 & $83-92$ & $63-85$ & 95 & 79 & 89 \\
\hline \multirow{2}{*}{ PET } & Maemura et al38 & 2006 & \multirow{2}{*}{$87-100$} & \multirow{2}{*}{$67-77$} & \multirow{2}{*}{94} & 100 & 250 \\
\hline & Delbeke et al111 & 1999 & & & & 100 & $85-95$ \\
\hline
\end{tabular}

Abbreviations: Ultrasound (US), Endoscopic ultrasound (EUS), Computed tomography (CT), Multi detector computed tomography (MDCT), Positron emission tomography (PET)

Table 7. Summary of the performance characteristics of imaging tests for the diagnosis of pancreatic cancer

\subsection{Cystic fluid markers}

Several markers can be measured in the fluid aspirated from the pancreatic lesions during EUS to differentiate mucinous from non mucinous cysts. The most commonly used are; CEA, carbohydrate antigen (CA) 19-9, CA 72-4, and CA 15-3 116. CEA appears be the most useful as levels higher than $192 \mathrm{ng} / \mathrm{ml}$ had an accuracy of $79 \%$ for mucinous lesion characterization and was superior to cytology and EUS morphology 103.

Other markers such as amylase and lipase are important in the evaluation of cystic pancreatic lesions. Amylase is usually elevated in inflammatory cysts like pseudocysts but also in IPMN due to communication between the cystic lesion and the pancreatic duct. Amylase level less than $250 \mathrm{U} / \mathrm{L}$ favors the diagnosis of benign or malignant cystic neoplasms versus pancreatic pseudocysts (sensitivity $44 \%$, specificity $98 \%$ ) 117 . 
Molecular markers are recently considered a more reliable alternative. A multicenter study on pancreatic cyst fluid DNA analysis demonstrated a strong association of mucinous cystic neoplasms with K-ras mutations occurring with other loss of heterozygosity ( $\mathrm{LOH}$ ) mutations ${ }^{118}$. Shen et al ${ }^{119}$ assessed the correlation between this molecular diagnosis with a clinical consensus diagnosis for PCLs defined by histology, malignant cytology, or two concordant tests (such as EUS, cytology, or CEA>_192 ng/ml for mucinous cysts). The study showed that the two diagnostic methods correlated well and molecular analysis of pancreatic cyst fluid added diagnostic value to the preoperative diagnosis.

\section{Conclusion}

Pancreatic cystic lesions are detected more frequently than in the past due to more sensitive imaging modalities. The differentiation between benign and malignant cystic lesions is often challenging. EUS and EUS-FNA have become a leading modality for the differential diagnosis of these lesions as it provides imaging characteristics and the possibility of obtaining cytology or fluid samples with high sensitivity and specificity. Characterization of cystic morphology by other imaging studies should be supplemented by EUS-FNA as cytology, tumor markers and DNA analysis can further characterize these lesions and increase the diagnostic accuracy of premalignant and malignant cysts.

\section{Summary}

Despite the advancement of other cross sectional imaging tests, EUS appears to have a higher sensitivity in detecting small pancreatic neoplasms in comparison to CT. On the other hand EUS does not appear to be accurate enough in assessing the invasion of SMA and SMV and respectability of locally advanced tumors. Recent studies have shown improved diagnostic performance of EUS with the use of parenteral contrast agents and EUS-FNA plays a key role when. tissue diagnosis is needed.

\section{References}

[1] DiMagno EP, Buxton JL, Regan PT, et al. Ultrasonic endoscope. Lancet 1980;1:629-31.

[2] Yasuda K, Mukai H, Cho E, Nakajima M, Kawai K. The use of endoscopic ultrasonography in the diagnosis and staging of carcinoma of the papilla of Vater. Endoscopy 1988;20 Suppl 1:218-22.

[3] Rosch T, Lorenz R, Braig C, et al. Endoscopic ultrasound in pancreatic tumor diagnosis. Gastrointest Endosc 1991;37:347-52.

[4] Vilmann P, Hancke S. [Endoscopic ultrasound scanning of the upper gastrointestinal tract. Preliminary results]. Ugeskr Laeger 1991;153:422-5.

[5] Bhutani MS, Hawes RH, Baron PL, et al. Endoscopic ultrasound guided fine needle aspiration of malignant pancreatic lesions. Endoscopy 1997;29:854-8.

[6] Chang KJ, Katz KD, Durbin TE, et al. Endoscopic ultrasound-guided fine-needle aspiration. Gastrointest Endosc 1994;40:694-9.

[7] Gress FG, Savides TJ, Sandler A, et al. Endoscopic ultrasonography, fine-needle aspiration biopsy guided by endoscopic ultrasonography, and computed tomography in the preoperative staging of non-small-cell lung cancer: a comparison study. Ann Intern Med 1997;127:604-12. 
[8] Giovannini M, Seitz JF. Endoscopic ultrasonography with a linear-type echoendoscope in the evaluation of 94 patients with pancreatobiliary disease. Endoscopy 1994;26:579-85.

[9] Chang KJ, Nguyen P, Erickson RA, Durbin TE, Katz KD. The clinical utility of endoscopic ultrasound-guided fine-needle aspiration in the diagnosis and staging of pancreatic carcinoma. Gastrointest Endosc 1997;45:387-93.

[10] Santo E. Pancreatic cancer imaging: which method? JOP 2004;5:253-7.

[11] Jemal A, Siegel R, Ward E, Hao Y, Xu J, Thun MJ. Cancer statistics, 2009. CA Cancer J Clin 2009;59:225-49.

[12] Lynch SM, Vrieling A, Lubin JH, et al. Cigarette smoking and pancreatic cancer: a pooled analysis from the pancreatic cancer cohort consortium. Am J Epidemiol 2009;170:403-13.

[13] Hassan MM, Bondy ML, Wolff RA, et al. Risk factors for pancreatic cancer: case-control study. Am J Gastroenterol 2007;102:2696-707.

[14] Iodice S, Gandini S, Maisonneuve P, Lowenfels AB. Tobacco and the risk of pancreatic cancer: a review and meta-analysis. Langenbecks Arch Surg 2008;393:535-45.

[15] Permert J, Ihse I, Jorfeldt L, von Schenck H, Arnqvist HJ, Larsson J. Pancreatic cancer is associated with impaired glucose metabolism. Eur J Surg 1993;159:101-7.

[16] Shaib YH, Davila JA, El-Serag HB. The epidemiology of pancreatic cancer in the United States: changes below the surface. Aliment Pharmacol Ther 2006;24:87-94.

[17] Sharma C, Eltawil KM, Renfrew PD, Walsh MJ, Molinari M. Advances in diagnosis, treatment and palliation of pancreatic carcinoma: 1990-2010. World J Gastroenterol 2011;17:867-97.

[18] Sener SF, Fremgen A, Menck HR, Winchester DP. Pancreatic cancer: a report of treatment and survival trends for 100,313 patients diagnosed from 1985-1995, using the National Cancer Database. J Am Coll Surg 1999;189:1-7.

[19] Gandolfi L, Torresan F, Solmi L, Puccetti A. The role of ultrasound in biliary and pancreatic diseases. Eur J Ultrasound 2003;16:141-59.

[20] Bottger TC, Boddin J, Duber C, Heintz A, Kuchle R, Junginger T. Diagnosing and staging of pancreatic carcinoma-what is necessary? Oncology 1998;55:122-9.

[21] Palazzo L, Roseau G, Gayet B, et al. Endoscopic ultrasonography in the diagnosis and staging of pancreatic adenocarcinoma. Results of a prospective study with comparison to ultrasonography and CT scan. Endoscopy 1993;25:143-50.

[22] Baarir N, Amouyal G, Faintuch JM, Houry S, Huguier M. [Comparison of color Doppler ultrasonography and endoscopic ultrasonography for preoperative evaluation of the mesenteric-portal axis in pancreatic lesions]. Chirurgie 1998;123:445-9.

[23] Casadei R, Ghigi G, Gullo L, et al. Role of color Doppler ultrasonography in the preoperative staging of pancreatic cancer. Pancreas 1998;16:26-30.

[24] Tamm EP, Silverman PM, Charnsangavej C, Evans DB. Diagnosis, staging, and surveillance of pancreatic cancer. AJR Am J Roentgenol 2003;180:1311-23.

[25] Choi BI, Chung MJ, Han JK, Han MC, Yoon YB. Detection of pancreatic adenocarcinoma: relative value of arterial and late phases of spiral CT. Abdom Imaging 1997;22:199-203.

[26] Bronstein YL, Loyer EM, Kaur H, et al. Detection of small pancreatic tumors with multiphasic helical CT. AJR Am J Roentgenol 2004;182:619-23. 
[27] Megibow AJ, Zhou XH, Rotterdam H, et al. Pancreatic adenocarcinoma: CT versus MR imaging in the evaluation of resectability--report of the Radiology Diagnostic Oncology Group. Radiology 1995;195:327-32.

[28] Gangi S, Fletcher JG, Nathan MA, et al. Time interval between abnormalities seen on CT and the clinical diagnosis of pancreatic cancer: retrospective review of CT scans obtained before diagnosis. AJR Am J Roentgenol 2004;182:897-903.

[29] Ohwada S, Ogawa T, Tanahashi Y, et al. Fibrin glue sandwich prevents pancreatic fistula following distal pancreatectomy. World J Surg 1998;22:494-8.

[30] Vargas R, Nino-Murcia M, Trueblood W, Jeffrey RB, Jr. MDCT in Pancreatic adenocarcinoma: prediction of vascular invasion and resectability using a multiphasic technique with curved planar reformations. AJR Am J Roentgenol 2004;182:419-25.

[31] Diehl SJ, Lehmann KJ, Sadick M, Lachmann R, Georgi M. Pancreatic cancer: value of dual-phase helical CT in assessing resectability. Radiology 1998;206:373-8.

[32] Lu DS, Reber HA, Krasny RM, Kadell BM, Sayre J. Local staging of pancreatic cancer: criteria for unresectability of major vessels as revealed by pancreatic-phase, thinsection helical CT. AJR Am J Roentgenol 1997;168:1439-43.

[33] Schima W, Fugger R, Schober E, et al. Diagnosis and staging of pancreatic cancer: comparison of mangafodipir trisodium-enhanced MR imaging and contrastenhanced helical hydro-CT. AJR Am J Roentgenol 2002;179:717-24.

[34] Ichikawa $T$, Haradome $H$, Hachiya $J$, et al. Pancreatic ductal adenocarcinoma: preoperative assessment with helical CT versus dynamic MR imaging. Radiology 1997;202:655-62.

[35] Irie H, Honda H, Kaneko K, Kuroiwa T, Yoshimitsu K, Masuda K. Comparison of helical CT and MR imaging in detecting and staging small pancreatic adenocarcinoma. Abdom Imaging 1997;22:429-33.

[36] Romijn MG, Stoker J, van Eijck CH, van Muiswinkel JM, Torres CG, Lameris JS. MRI with mangafodipir trisodium in the detection and staging of pancreatic cancer. J Magn Reson Imaging 2000;12:261-8.

[37] Andersson M, Kostic S, Johansson M, Lundell L, Asztely M, Hellstrom M. MRI combined with MR cholangiopancreatography versus helical CT in the evaluation of patients with suspected periampullary tumors: a prospective comparative study. Acta Radiol 2005;46:16-27.

[38] Maemura K, Takao S, Shinchi H, et al. Role of positron emission tomography in decisions on treatment strategies for pancreatic cancer. J Hepatobiliary Pancreat Surg 2006;13:435-41.

[39] Higashi T, Saga T, Nakamoto $Y$, et al. Diagnosis of pancreatic cancer using fluorine-18 fluorodeoxyglucose positron emission tomography (FDG PET) --usefulness and limitations in "clinical reality". Ann Nucl Med 2003;17:261-79.

[40] Wakabayashi H, Nishiyama Y, Otani T, et al. Role of 18F-fluorodeoxyglucose positron emission tomography imaging in surgery for pancreatic cancer. World J Gastroenterol 2008;14:64-9.

[41] Reese SA, Traverso LW, Jacobs TW, Longnecker DS. Solid serous adenoma of the pancreas: a rare variant within the family of pancreatic serous cystic neoplasms. Pancreas 2006;33:96-9. 
[42] Stern JR, Frankel WL, Ellison EC, Bloomston M. Solid serous microcystic adenoma of the pancreas. World J Surg Oncol 2007;5:26.

[43] Institute TUNC. Surveiilance Epidemiology and End Results (SEER) database. 2007. Available from: URL:http://seer.cancer.gov/. 2007.

[44] Buchler MW, Wagner M, Schmied BM, Uhl W, Friess H, Z'Graggen K. Changes in morbidity after pancreatic resection: toward the end of completion pancreatectomy. Arch Surg 2003;138:1310-4; discussion 5.

[45] Birkmeyer JD, Siewers AE, Finlayson EV, et al. Hospital volume and surgical mortality in the United States. N Engl J Med 2002;346:1128-37.

[46] Cameron JL, Riall TS, Coleman J, Belcher KA. One thousand consecutive pancreaticoduodenectomies. Ann Surg 2006;244:10-5.

[47] Sahani DV, Shah ZK, Catalano OA, Boland GW, Brugge WR. Radiology of pancreatic adenocarcinoma: current status of imaging. J Gastroenterol Hepatol 2008;23:23-33.

[48] Yamao K, Okubo K, Sawaka A, et al. Endolumenal ultrasonography in the diagnosis of pancreatic diseases. Abdom Imaging 2003;28:545-55.

[49] Moesinger RC, Talamini MA, Hruban RH, Cameron JL, Pitt HA. Large cystic pancreatic neoplasms: pathology, resectability, and outcome. Ann Surg Oncol 1999;6:682-90.

[50] Oberg K. Neuroendocrine gastrointestinal tumours. Ann Oncol 1996;7:453-63.

[51] Fritscher-Ravens A, Izbicki JR, Sriram PV, et al. Endosonography-guided, fine-needle aspiration cytology extending the indication for organ-preserving pancreatic surgery. Am J Gastroenterol 2000;95:2255-60.

[52] Baron PL, Kay C, Hoffman B. Pancreatic imaging. Surg Oncol Clin N Am 1999;8:35-58.

[53] Muller MF, Meyenberger C, Bertschinger P, Schaer R, Marincek B. Pancreatic tumors: evaluation with endoscopic US, CT, and MR imaging. Radiology 1994;190:745-51.

[54] Chang KJ. Endoscopic ultrasound-guided fine needle aspiration in the diagnosis and staging of pancreatic tumors. Gastrointest Endosc Clin N Am 1995;5:723-34.

[55] Legmann P, Vignaux O, Dousset B, et al. Pancreatic tumors: comparison of dual-phase helical CT and endoscopic sonography. AJR Am J Roentgenol 1998;170:1315-22.

[56] Mertz HR, Sechopoulos P, Delbeke D, Leach SD. EUS, PET, and CT scanning for evaluation of pancreatic adenocarcinoma. Gastrointest Endosc 2000;52:367-71.

[57] Bhutani MS, Gress FG, Giovannini M, et al. The No Endosonographic Detection of Tumor (NEST) Study: a case series of pancreatic cancers missed on endoscopic ultrasonography. Endoscopy 2004;36:385-9.

[58] Erickson RA, Sayage-Rabie L, Avots-Avotins A. Clinical utility of endoscopic ultrasound-guided fine needle aspiration. Acta Cytol 1997;41:1647-53.

[59] Barthet M, Portal I, Boujaoude J, Bernard JP, Sahel J. Endoscopic ultrasonographic diagnosis of pancreatic cancer complicating chronic pancreatitis. Endoscopy 1996;28:487-91.

[60] Binmoeller KF, Thul R, Rathod V, et al. Endoscopic ultrasound-guided, 18-gauge, fine needle aspiration biopsy of the pancreas using a $2.8 \mathrm{~mm}$ channel convex array echoendoscope. Gastrointest Endosc 1998;47:121-7.

[61] Gress F, Gottlieb K, Sherman S, Lehman G. Endoscopic ultrasonography-guided fineneedle aspiration biopsy of suspected pancreatic cancer. Ann Intern Med 2001;134:459-64. 
[62] Wiersema MJ, Vilmann P, Giovannini M, Chang KJ, Wiersema LM. Endosonographyguided fine-needle aspiration biopsy: diagnostic accuracy and complication assessment. Gastroenterology 1997;112:1087-95.

[63] Erickson RA, Garza AA. Impact of endoscopic ultrasound on the management and outcome of pancreatic carcinoma. Am J Gastroenterol 2000;95:2248-54.

[64] Bhutani MS. Endoscopic ultrasonography in pancreatic disease. Semin Gastrointest Dis 1998;9:51-60.

[65] Gress F, Savides T, Cummings O, et al. Radial scanning and linear array endosonography for staging pancreatic cancer: a prospective randomized comparison. Gastrointest Endosc 1997;45:138-42.

[66] Micames C, Jowell PS, White R, et al. Lower frequency of peritoneal carcinomatosis in patients with pancreatic cancer diagnosed by EUS-guided FNA vs. percutaneous FNA. Gastrointest Endosc 2003;58:690-5.

[67] Hollerbach S, Klamann A, Topalidis T, Schmiegel WH. Endoscopic ultrasonography (EUS) and fine-needle aspiration (FNA) cytology for diagnosis of chronic pancreatitis. Endoscopy 2001;33:824-31.

[68] Hayashi Y, Nakazawa S, Kimoto E, Naito Y, Morita K. Clinicopathologic analysis of endoscopic ultrasonograms in pancreatic mass lesions. Endoscopy 1989;21:121-5.

[69] Canto MI, Goggins M, Hruban RH, et al. Screening for early pancreatic neoplasia in high-risk individuals: a prospective controlled study. Clin Gastroenterol Hepatol 2006;4:766-81; quiz 665.

[70] Canto MI, Goggins M, Yeo CJ, et al. Screening for pancreatic neoplasia in high-risk individuals: an EUS-based approach. Clin Gastroenterol Hepatol 2004;2:606-21.

[71] Rosch T, Braig C, Gain T, et al. Staging of pancreatic and ampullary carcinoma by endoscopic ultrasonography. Comparison with conventional sonography, computed tomography, and angiography. Gastroenterology 1992;102:188-99.

[72] Akahoshi K, Chijiiwa Y, Nakano I, et al. Diagnosis and staging of pancreatic cancer by endoscopic ultrasound. Br J Radiol 1998;71:492-6.

[73] Cannon ME, Carpenter SL, Elta GH, et al. EUS compared with CT, magnetic resonance imaging, and angiography and the influence of biliary stenting on staging accuracy of ampullary neoplasms. Gastrointest Endosc 1999;50:27-33.

[74] Ahmad NA, Lewis JD, Ginsberg GG, Rosato EF, Morris JB, Kochman ML. EUS in preoperative staging of pancreatic cancer. Gastrointest Endosc 2000;52:463-8.

[75] Meining A, Dittler HJ, Wolf A, et al. You get what you expect? A critical appraisal of imaging methodology in endosonographic cancer staging. Gut 2002;50:599-603.

[76] Soriano A, Castells A, Ayuso C, et al. Preoperative staging and tumor resectability assessment of pancreatic cancer: prospective study comparing endoscopic ultrasonography, helical computed tomography, magnetic resonance imaging, and angiography. Am J Gastroenterol 2004;99:492-501.

[77] Eloubeidi MA, Chen VK, Eltoum IA, et al. Endoscopic ultrasound-guided fine needle aspiration biopsy of patients with suspected pancreatic cancer: diagnostic accuracy and acute and 30-day complications. Am J Gastroenterol 2003;98:2663-8.

[78] Bao PQ, Johnson JC, Lindsey EH, et al. Endoscopic ultrasound and computed tomography predictors of pancreatic cancer resectability. J Gastrointest Surg 2008;12:10-6; discussion 6. 
[79] Helmstaedter L, Riemann JF. Pancreatic cancer--EUS and early diagnosis. Langenbecks Arch Surg 2008;393:923-7.

[80] Hartwig W, Schneider L, Diener MK, Bergmann F, Buchler MW, Werner J. Preoperative tissue diagnosis for tumours of the pancreas. Br J Surg 2009;96:5-20.

[81] Spinelli KS, Fromwiller TE, Daniel RA, et al. Cystic pancreatic neoplasms: observe or operate. Ann Surg 2004;239:651-7; discussion 7-9.

[82] Laffan TA, Horton KM, Klein AP, et al. Prevalence of unsuspected pancreatic cysts on MDCT. AJR Am J Roentgenol 2008;191:802-7.

[83] Volkan Adsay N. Cystic lesions of the pancreas. Mod Pathol 2007;20 Suppl 1:S71-93.

[84] Ishikawa T, Takeda K, Itoh M, et al. Prevalence of pancreatic cystic lesions including intraductal papillary mucinous neoplasms in patients with end-stage renal disease on hemodialysis. Pancreas 2009;38:175-9.

[85] Warshaw AL, Rutledge PL. Cystic tumors mistaken for pancreatic pseudocysts. Ann Surg 1987;205:393-8.

[86] Kloppel G, Luttges J. WHO-classification 2000: exocrine pancreatic tumors. Verh Dtsch Ges Pathol 2001;85:219-28.

[87] Friedel DM, Abraham B, Georgiou N, Stavropoulos SN, Grendell JH, Katz DS. Pancreatic cystic neoplasms. South Med J;103:51-7.

[88] Bose D, Tamm E, Liu J, et al. Multidisciplinary management strategy for incidental cystic lesions of the pancreas. J Am Coll Surg;211:205-15.

[89] Karlson BM, Ekbom A, Lindgren PG, Kallskog V, Rastad J. Abdominal US for diagnosis of pancreatic tumor: prospective cohort analysis. Radiology 1999;213:107-11.

[90] Mathieu D, Guigui B, Valette PJ, et al. Pancreatic cystic neoplasms. Radiol Clin North Am 1989;27:163-76.

[91] Le Borgne J, de Calan L, Partensky C. Cystadenomas and cystadenocarcinomas of the pancreas: a multiinstitutional retrospective study of 398 cases. French Surgical Association. Ann Surg 1999;230:152-61.

[92] Procacci C, Biasiutti C, Carbognin G, et al. Characterization of cystic tumors of the pancreas: CT accuracy. J Comput Assist Tomogr 1999;23:906-12.

[93] Bassi C, Salvia R, Molinari E, Biasutti C, Falconi M, Pederzoli P. Management of 100 consecutive cases of pancreatic serous cystadenoma: wait for symptoms and see at imaging or vice versa? World J Surg 2003;27:319-23.

[94] Minami M, Itai Y, Ohtomo K, Yoshida H, Yoshikawa K, Iio M. Cystic neoplasms of the pancreas: comparison of MR imaging with CT. Radiology 1989;171:53-6.

[95] Koito K, Namieno T, Ichimura T, et al. Mucin-producing pancreatic tumors: comparison of MR cholangiopancreatography with endoscopic retrograde cholangiopancreatography. Radiology 1998;208:231-7.

[96] Adler DG, Jacobson BC, Davila RE, et al. ASGE guideline: complications of EUS. Gastrointest Endosc 2005;61:8-12.

[97] Mizuno N, Bhatia V, Hosoda W, et al. Histological diagnosis of autoimmune pancreatitis using EUS-guided trucut biopsy: a comparison study with EUS-FNA. J Gastroenterol 2009;44:742-50.

[98] Hawes RH. Indications for EUS-directed FNA. Endoscopy 1998;30 Suppl 1:A155-7.

[99] Rosen CB, Heimbach JK, Gores GJ. Liver transplantation for cholangiocarcinoma. Transpl Int;23:692-7. 
[100] Ahmad NA, Kochman ML, Lewis JD, Ginsberg GG. Can EUS alone differentiate between malignant and benign cystic lesions of the pancreas? Am J Gastroenterol 2001;96:3295-300.

[101] Ahmad NA, Kochman ML, Brensinger C, et al. Interobserver agreement among endosonographers for the diagnosis of neoplastic versus non-neoplastic pancreatic cystic lesions. Gastrointest Endosc 2003;58:59-64.

[102] Frossard JL, Amouyal P, Amouyal G, et al. Performance of endosonography-guided fine needle aspiration and biopsy in the diagnosis of pancreatic cystic lesions. Am J Gastroenterol 2003;98:1516-24.

[103] Brugge WR, Lewandrowski K, Lee-Lewandrowski E, et al. Diagnosis of pancreatic cystic neoplasms: a report of the cooperative pancreatic cyst study. Gastroenterology 2004;126:1330-6.

[104] Sedlack R, Affi A, Vazquez-Sequeiros E, Norton ID, Clain JE, Wiersema MJ. Utility of EUS in the evaluation of cystic pancreatic lesions. Gastrointest Endosc 2002;56:543-7.

[105] Niederau C, Grendell JH. Diagnosis of pancreatic carcinoma. Imaging techniques and tumor markers. Pancreas 1992;7:66-86.

[106] Tanaka S, Kitamra T, Yamamoto K, et al. Evaluation of routine sonography for early detection of pancreatic cancer. Jpn J Clin Oncol 1996;26:422-7.

[107] Candiani F, Meduri F, Norberto L, Calderone M. [Contrast media in ultrasonography. Venous involvement in tumors of the head of the pancreas]. Radiol Med 1998;95:29-33.

[108] Calculli L, Casadei R, Amore B, et al. The usefulness of spiral Computed Tomography and colour-Doppler ultrasonography to predict portal-mesenteric trunk involvement in pancreatic cancer. Radiol Med 2002;104:307-15.

[109] Dietrich CF, Braden B, Hocke M, Ott M, Ignee A. Improved characterisation of solitary solid pancreatic tumours using contrast enhanced transabdominal ultrasound. J Cancer Res Clin Oncol 2008;134:635-43.

[110] Park HS, Lee JM, Choi HK, Hong SH, Han JK, Choi BI. Preoperative evaluation of pancreatic cancer: comparison of gadolinium-enhanced dynamic MRI with MR cholangiopancreatography versus MDCT. J Magn Reson Imaging 2009;30:586-95.

[111] Delbeke D, Rose DM, Chapman WC, et al. Optimal interpretation of FDG PET in the diagnosis, staging and management of pancreatic carcinoma. J Nucl Med 1999;40:1784-91.

[112] Bruno M, Bosco M, Carucci P, et al. Preliminary experience with a new cytology brush in EUS-guided FNA. Gastrointest Endosc 2009;70:1220-4.

[113] Al-Haddad M, Gill KR, Raimondo M, et al. Safety and efficacy of cytology brushings versus standard fine-needle aspiration in evaluating cystic pancreatic lesions: a controlled study. Endoscopy;42:127-32.

[114] Jacobson BC, Baron TH, Adler DG, et al. ASGE guideline: The role of endoscopy in the diagnosis and the management of cystic lesions and inflammatory fluid collections of the pancreas. Gastrointest Endosc 2005;61:363-70.

[115] Shah JN, Fraker D, Guerry D, Feldman M, Kochman ML. Melanoma seeding of an EUS-guided fine needle track. Gastrointest Endosc 2004;59:923-4. 
[116] Repak R, Rejchrt S, Bartova J, Malirova E, Tycova V, Bures J. Endoscopic ultrasonography (EUS) and EUS-guided fine-needle aspiration with cyst fluid analysis in pancreatic cystic neoplasms. Hepatogastroenterology 2009;56:629-35.

[117] van der Waaij LA, van Dullemen HM, Porte RJ. Cyst fluid analysis in the differential diagnosis of pancreatic cystic lesions: a pooled analysis. Gastrointest Endosc 2005;62:383-9.

[118] Khalid A, Zahid M, Finkelstein SD, et al. Pancreatic cyst fluid DNA analysis in evaluating pancreatic cysts: a report of the PANDA study. Gastrointest Endosc 2009;69:1095-102.

[119] Shen J, Brugge WR, Dimaio CJ, Pitman MB. Molecular analysis of pancreatic cyst fluid: a comparative analysis with current practice of diagnosis. Cancer 2009;117:217-27. 


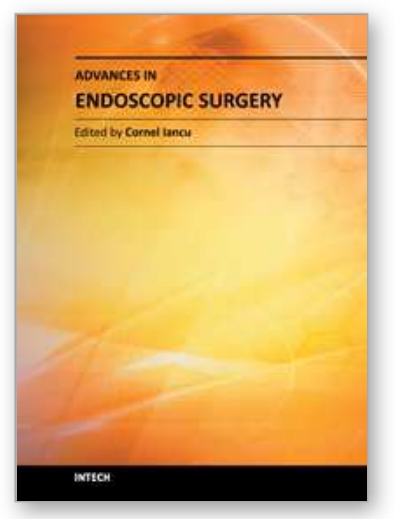

\author{
Advances in Endoscopic Surgery \\ Edited by Prof. Cornel lancu
}

ISBN 978-953-307-717-8

Hard cover, 444 pages

Publisher InTech

Published online 25, November, 2011

Published in print edition November, 2011

Surgeons from various domains have become fascinated by endoscopy with its very low complications rates, high diagnostic yields and the possibility to perform a large variety of therapeutic procedures. Therefore during the last 30 years, the number and diversity of surgical endoscopic procedures has advanced with many new methods for both diagnoses and treatment, and these achievements are presented in this book. Contributing to the development of endoscopic surgery from all over the world, this is a modern, educational, and engrossing publication precisely presenting the most recent development in the field. New technologies are described in detail and all aspects of both standard and advanced endoscopic maneuvers applied in gastroenterology, urogynecology, otorhinolaryngology, pediatrics and neurology are presented. The intended audience for this book includes surgeons from various specialities, radiologists, internists, and subspecialists.

\title{
How to reference
}

In order to correctly reference this scholarly work, feel free to copy and paste the following:

Karim M. Eltawil and Michele Molinari (2011). Endoscopic Ultrasound for Solid and Cystic Neoplasms of the Pancreas, Advances in Endoscopic Surgery, Prof. Cornel lancu (Ed.), ISBN: 978-953-307-717-8, InTech, Available from: http://www.intechopen.com/books/advances-in-endoscopic-surgery/endoscopic-ultrasound-forsolid-and-cystic-neoplasms-of-the-pancreas

\section{INTECH}

open science | open minds

\author{
InTech Europe \\ University Campus STeP Ri \\ Slavka Krautzeka 83/A \\ 51000 Rijeka, Croatia \\ Phone: +385 (51) 770447 \\ Fax: +385 (51) 686166 \\ www.intechopen.com
}

\author{
InTech China \\ Unit 405, Office Block, Hotel Equatorial Shanghai \\ No.65, Yan An Road (West), Shanghai, 200040, China \\ 中国上海市延安西路65号上海国际贵都大饭店办公楼405单元 \\ Phone: +86-21-62489820 \\ Fax: +86-21-62489821
}


(C) 2011 The Author(s). Licensee IntechOpen. This is an open access article distributed under the terms of the Creative Commons Attribution 3.0 License, which permits unrestricted use, distribution, and reproduction in any medium, provided the original work is properly cited. 